\title{
Forecasting and Backcasting: Predicting the Impact of Events on the Future
}

\section{Citation}

Ebert, Jane E. J., Daniel T. Gilbert, and Timothy D. Wilson. 2009. Forecasting and backcasting: Predicting the impact of events on the future. Journal of Consumer Research 36(3): 353-366.

\section{Published Version}

doi:10.1086/598793

\section{Permanent link}

http://nrs.harvard.edu/urn-3:HUL.InstRepos:3549374

\section{Terms of Use}

This article was downloaded from Harvard University's DASH repository, and is made available under the terms and conditions applicable to Other Posted Material, as set forth at http:// nrs.harvard.edu/urn-3:HUL.InstRepos:dash.current.terms-of-use\#LAA

\section{Share Your Story}

The Harvard community has made this article openly available.

Please share how this access benefits you. Submit a story.

\section{Accessibility}




\title{
Forecasting and Backcasting: Predicting the Impact of Events on the Future
}

\author{
JANE E. J. EBERT \\ DANIEL T. GILBERT \\ TIMOTHY D. WILSON*
}

\begin{abstract}
In many choices they make-for example, choosing between a movie and a play or deciding whether to attend a sports game shortly before a birthday partyconsumers are guided by how they expect an event will make them feel. They may predict their feelings by forecasting (imagining their feelings when the impacting event occurs, then considering how those feelings might change over time) or by backcasting (imagining their feelings in a future period, then considering how those feelings might be different were the impacting event to happen). Four studies show that backcasters expect events to have a greater hedonic impact than do forecasters, largely because they think more about the impacting event. The studies also reveal that backcasters consider other information that forecasters tend to ignore.
\end{abstract}

$\mathrm{W}$ hether choosing between a movie and a play, deciding whether to attend a sports game shortly before a birthday party, or selecting an indulgent breakfast treat in anticipation of a tough day at work, consumers are often guided by how they expect a consumption experience will make them feel. Indeed, anticipated feelings of pleasure, satisfaction, and regret determine a wide range of consumption decisions, including those involving monetary gambles, brand preference, pregnancy tests, dieting, junk food, overindulgence in alcohol, and more (Mellers and McGraw 2001; Richard, Van der Plight, and De Vries 1996; Shiv and Huber 2000; Simonson 1992; Zeelenberg et al. 1997).

How do consumers predict their feelings following a fu-

\footnotetext{
*Jane E. J. Ebert is assistant professor of marketing and logistics, University of Minnesota, Minneapolis, MN 55455 (jebert@umn.edu). Daniel T. Gilbert is Harvard College professor and professor of psychology, Harvard University, Cambridge, MA 02138 (gilbert@wjh.harvard.edu). Timothy D. Wilson is Sherrell J. Aston Professor of Psychology, University of Virginia, Charlottesville, VA 22904-4400 (tdw@virginia.edu). Correspondence: Jane E. J. Ebert. The authors gratefully acknowledge financial support from the Carlson School of Management and from research grant BCS-0722132 from the National Science Foundation to Daniel T. Gilbert and Timothy D. Wilson. In addition, the authors acknowledge the helpful input of the editor, associate editor, and reviewers. Finally, the authors thank Elizabeth Brown, Matthew Getman, Kate McHugh, Noelle Nelson, Jy Kyung Park, James Rattenbury, and Kelsey Webster for their assistance in the execution of these studies.
}

John Deighton served as editor and Baba Shiv served as associate editor for this article.

Electronically published March 25, 2009 ture consumption event? One approach is by forecasting - the consumer first considers how she is likely to feel in response to the event ("I'll be very unhappy if the Red Sox lose today") and then considers the effects of future circumstances, such as the passage of time and how she is likely to feel in a future period ("But I'll probably feel better in a few days with my birthday coming up"). Forecasting, as an approach to predicting the hedonic impact of a future event, has been widely studied in the literature (Coughlan and Connolly 2001; Dunn, Wilson, and Gilbert 2003; Finkenauer et al. 2007; Gaunt, Sindic, and Leyens 2005; Gilbert et al. 1998, 2004; Kahneman and Snell 1992; Loewenstein and Frederick 1997; Mellers 2000; Read and Van Leeuwen 1998; Snell, Gibbs, and Varey 1995; Wilson et al. 2000, 2005). A second approach that we propose for predicting the hedonic impact of a future event-backcasting - is one that has received much less attention. In backcasting, the consumer first considers how she is likely to feel in a future period ("I'm going to be happy in a few days because my birthday is coming up") and then considers the effects of the prior impacting event and the passage of time ("And if the Red Sox lose today it won't change that much"). Forecasting and backcasting are logically identical approaches to predicting the feelings following an impacting event: a consumer ends by making the same prediction using precisely the same information. However, these approaches reverse the order in which consumers consider information about how they will feel in a future period ("How will I feel a few days from now?") and information about the impacting event ("How will I feel if the Red Sox lose today?"). While they may be logically identical approaches 
to making hedonic predictions, the order in which information is considered in forecasting versus backcasting is likely to give rise to significant psychological differences, leading to different hedonic predictions for forecasters and backcasters, as this research will demonstrate.

In the next section we summarize factors that have been found to influence forecasting and propose differences in the information considered by forecasters and backcasters and the predictions they will make based on the psychological processes underlying these approaches to hedonic prediction. We then present four studies that test our propositions. Our studies enable us to make the following claims. First, backcasters and forecasters differ in the extent to which they consider the information relevant to hedonic impact predictions. Specifically, backcasters consider information about the impacting event and the future time period more than forecasters do, whereas they consider information about the elapsed time between the impacting event and a future period to a similar extent. Second, these differences will frequently lead backcasters to make more extreme hedonic impact predictions than forecasters.

\section{THEORETICAL BACKGROUND}

In this section, we discuss previous research on hedonic prediction, which has emphasized a forecasting approach. We then present our conceptualization of backcasting and contrast it with forecasting to specify a set of hypotheses that we test in this research.

\section{Forecasting}

Past research on hedonic predictions shows that consumers tend to mispredict their future feelings, typically overestimating the intensity and duration of their feelings following the impacting event (for recent reviews, see Gilbert and Wilson [2007]; Loewenstein and Angner [2003]; and, in consumer behavior, MacInnis, Patrick, and Park [2006]). Two primary causes of this impact bias are focalism, where people overestimate how much they will think about the impacting event while underestimating the effect of other events on their thoughts and feelings (Wilson et al. 2000), and immune neglect, where people fail to appreciate how readily they will adapt emotionally to the impacting event and so underestimate how quickly their feelings dissipate over time (Gilbert et al. 1998; Snell et al. 1995).

We can also express each of these explanations in terms of predictors' use of relevant information when making their predictions. For hedonic predictions ("How will I feel on my birthday if the Red Sox lose today?"), three types of information are relevant: information about the impacting event ("How will I feel if the Red Sox lose today?"), information about the future period ("How will I feel on my birthday?"), and information about the elapsed time between the two ("How long is it from today to my birthday?"). Reexpressing the focalism and immune neglect explanations in terms of consideration of information, we can say that, when people predict the hedonic impact of an event, they tend to consider impacting event information too much and consider future period information too little (focalism) and consider elapsed time information too little (immune neglect).

Although prior research tells us something about how much people consider these three types of information when predicting the hedonic impact of an event, that research has typically emphasized a forecasting approach to hedonic prediction by $(a)$ explicitly directing participants to forecast - that is, by asking participants to predict their feelings immediately following an event and then to predict their feelings in some future period after the event (e.g., in Finkenauer et al. 2007; Gaunt et al. 2005; Gilbert et al. 2004; Wilson et al. 2000, 2005)—or (b) asking participants to consider the hedonic impact of a current event in some future period (e.g., in Coughlan and Connolly 2001; Dunn et al. 2003; Gilbert et al. 1998; Kahneman and Snell 1992; Loewenstein and Frederick 1997; Mellers 2000; Read and Van Leeuwen 1998; Snell et al. 1995).

\section{How Forecasters and Backcasters Differ}

But forecasting is not the only way by which consumers may predict the hedonic impact of an event. For example, when forming affective goals ("I want to feel happy tomorrow for my birthday"), consumers are likely to first consider their feelings at the future period before considering how those feelings might differ if an event occurred ("If I see the Red Sox today and they lose, that would ruin my birthday"; also suggested in MacInnis et al. [2006]). We refer to this prediction method as "backcasting," inspired by another literature in which subjects consider the impact of events on the future, that of strategic planning, which discusses two similar prediction approaches (e.g., Holmberg and Robert 2000; Noori et al. 1999). A manager backcasts by identifying a desired future state and then considering which of several strategies in the present is most likely to bring that state about, and a manager forecasts by identifying several strategies in the present and then considering the different future states that each strategy is likely to cause. (Also see Morris and Ward [2005] for similar planning approaches invoked by individuals solving cognitive tasks.)

Forecasting and backcasting are logically identical methods for consumers to predict their future feelings after a consumption event: in both cases a consumer ends by making the same prediction of his or her feelings in a particular future state given the occurrence of the event, and in both cases the person has and can use precisely the same information. Nonetheless, the two methods reverse the order in which consumers consider information about how they will feel in a future period ("How will I feel on my birthday?") and information about the impacting event ("How will I feel if the Red Sox lose today?"), and although the order of information makes no logical difference in a prediction such as this, it can make a significant psychological difference.

How will backcasters' hedonic predictions differ from those of forecasters? We expect that backcasters will frequently make more extreme hedonic predictions than forecasters will because of differences in how they consider 
relevant information. First, we expect that backcasters are likely to consider information about the impacting event more than forecasters, leading them to make more extreme hedonic predictions for both positive and negative impacting events. People typically weight the unique aspects of the subject of a comparison more heavily than the referent of the comparison (Dunning and Parpal 1989; Tversky 1977; Tversky and Gati 1978), and the subject and referent differ for forecasting and backcasting. A forecaster first considers her hedonic response to an impacting event (the referent) and then considers the effects of the passage of time (the subject). A backcaster first considers how she is likely to feel in a future period (the referent) and then considers the effects of the prior occurrence of the impacting event and the passage of time (the subject). This implies that consumers will consider impacting event information more when backcasting than when forecasting.

Second, we expect that information about the impacting event will have more impact on hedonic predictions than the other information they consider. As past research on the impact bias shows, people often ignore information about the future period (Lam et al. 2005; Wilson et al. 2000) and misunderstand how quickly feelings dissipate with elapsed time (Gilbert et al. 1998; Snell et al. 1995), which causes them to overestimate the hedonic impact of events. There are likely to be limits to this difference in the impact of impacting event, elapsed time, and future period information; for example, with very long elapsed times (e.g., years) and unusual future periods (e.g., the birth of a child), the relative influence of impacting event information may be small. Nonetheless, in many circumstances we expect that the impacting event will have a greater influence on predictors than information about the future period and elapsed time.

In combination, these two arguments lead to our first two hypotheses:

H1: Backcasters will make more extreme hedonic predictions than forecasters for both positive and negative impacting events.

H2: This difference in predictions will occur because backcasters consider impacting event information more than forecasters do.

Although predictors tend to ignore information about the future period, they will incorporate this information into their hedonic predictions when forced to consider it (Lam et al. 2005; Wilson et al. 2000). This suggests that backcasters, who first consider their feelings in a future period, are likely to show greater consideration of future period information than forecasters in the hedonic predictions they make. Considering this information could change hedonic predictions in one of two ways. Predictors may either expect that events in the future period will distract them from thinking about the impacting event ("At my birthday party I won't have time to think about the Red Sox losing"; Wilson et al. 2000) or expect that their feelings in the future period will add to their feelings following the impacting event ("My birthday party will help me feel better if the Red Sox lose, and if the Red Sox win, my party will make me even happier"; Linville and Fischer 1991). Given this uncertainty in the effect on hedonic predictions, we simply hypothesize that:

H3: Backcasters will consider future period information more than forecasters will in making their hedonic impact predictions.

Finally, forecasters and backcasters obtain information about the elapsed time between the impacting event and the future period at the same point. Backcasters first consider future period and then impacting event information, and forecasters first consider impacting event and then future period information, but information about both the timing of the impacting event and the timing of the future period is needed to infer elapsed time information ("There are three days between the Red Sox game and my birthday"). Since they will obtain this information at the same point, we expect that backcasters and forecasters will consider the elapsed time information to a similar extent.

H4: Backcasters and forecasters will not differ in their consideration of elapsed time information.

We tested these hypotheses in four studies in which participants were guided to make hedonic predictions by forecasting or backcasting, and we examined the influence of three types of information (impacting event information, future period information, and elapsed time information) on those predictions.

\section{STUDY 1A}

In this first study, we sought to discover what predictors think about when making hedonic predictions. Participants predicted how they would feel either 1 or 2 weeks hence if a positive impacting event (winning funds for car expenses) were to happen shortly. Before making this prediction, forecasters first predicted how they would feel when the impacting event occurred, and backcasters first predicted how they would feel in general either 1 or 2 weeks hence. Participants then listed the thoughts they had while making predictions. We expected that backcasters and forecasters would differ in the predictions they made and in the information they considered. In particular, we expected that backcasters would make more extreme predictions and would think more about impacting event information (relative to other information) than forecasters would.

\section{Method}

Participants. Participants were students who were recruited in a public place on the University of Minnesota campus to complete a questionnaire in exchange for candy. Of the 99 participants who completed the questionnaire, 58 
were female and 41 were male. The participants' mean age was 21.2 years $(\mathrm{SD}=4.3$ years).

Procedure. Participants were randomly assigned to a predictor condition (backcaster or forecaster) and an elapsed time condition ( 1 week or 2 weeks). All participants answered three questions. First, they all answered a baseline question about their usual mood: "How do you usually feel in general?" Second, participants in the forecaster condition estimated their feelings immediately after the impacting event ("Imagine that you bought a used car from a dealer a few months ago. Later today you find out from the dealer that you have won $\$ 1,000$ in a draw for recent customers to spend on any expenses for your car (to use when and where you want). How will you feel in general at the moment you find that out?"), whereas participants in the backcaster condition estimated their feelings in the future period ("How will you feel in general 1 week [2 weeks] from today?"). Third and finally, all participants predicted how they would feel in the future period if the impacting event occurred (their hedonic predictions). Specifically, they were asked: "Imagine that you bought a used car from a dealer a few months ago. Later today you find out from the dealer that you have won $\$ 1,000$ in a draw for recent customers to spend on any expenses for your car (to use when and where you want). How will you feel in general 1 week [2 weeks] from today?" Participants answered these questions using a 9-point scale ( $1=$ very unhappy, $5=$ neither happy nor unhappy, 9 = very happy). Participants then immediately described "every thought or idea that you were considering as you tried to predict your feelings." To ensure that participants considered the information in the proper order, each question was presented on a new page of a paper booklet.

\section{Results}

Analyses of baseline mood measures in this and subsequent studies occasionally revealed differences between conditions, and thus they were used as covariates in this and subsequent studies (as suggested by Tabachnick and Fidell [1996]).

Participants' hedonic predictions were submitted to a 2 (predictor: forecaster or backcaster) $\times 2$ (elapsed time: 1 week or 2 weeks) ANCOVA with the baseline mood ratings as the covariate. The analysis revealed only a main effect of predictor $(F(1,94)=14.73, p<.001$, eta $=.37)$, such that backcasters $(M=7.73)$ predicted greater influence of the impacting event than did forecasters $(M=6.85)$.

Backcasters and forecasters made different hedonic predictions. Did they also differ in what they thought about when making those predictions? Six participants did not list any thoughts. Of the remaining 93 participants, 89 (96\%) mentioned the impacting event in some form: 39 described thoughts focused only on the impacting event (i.e., winning $\$ 1,000$ for car expenses), and 50 mentioned the impacting event alongside some mention of the future. For example, one participant described thinking, "What else would be going on in a week? Would the happiness from winning last the week?" Participants' thoughts were coded, by a coder who was blind to condition, as being focused on $(a)$ the event only, $(b)$ the future plus the event, or $(c)$ other. The focus of participants' thoughts varied by condition $\left(\chi^{2}(2,93)=\right.$ $9.60, p=.008)$, such that backcasters focused more on the impacting event alone (event only: 26 of 93; future plus event: 21 of 93; other: 0 of 93) than did forecasters (event only: 13 of 93; future plus event: 29 of 93; other: 4 of 93). This difference remained significant when the "other" category was excluded $(p=.02)$.

\section{Discussion}

Backcasters were more likely than forecasters to predict that a positive event would have considerable hedonic impact in the future, making more extreme hedonic predictions on average. Backcasters and forecasters also differed in the thoughts they had when making those predictions. Although the impacting event was considered by almost all predictors, backcasters were more likely to focus on the event alone than were forecasters.

The elapsed time manipulation had no significant effects, perhaps because participants expected the affective impact of this event to last more than 2 weeks. Alternatively, this may reflect some insensitivity to variation in elapsed time (Varey and Kahneman 1992).

\section{STUDY 1B}

In study 1a, we found that backcasters were more likely than forecasters to focus on impacting event information when making hedonic predictions. In this study, we continued our exploration of predictors' thoughts by explicitly asking participants the extent to which they thought about the effects of the other two types of information relevant to hedonic predictions: elapsed time and future period. In addition, because study 1a used only a positive event, it is not clear whether backcasters made more extreme predictions or more positive predictions than forecasters. In this study (and in subsequent studies), we used both positive and negative impacting events.

As in study 1a, backcasters and forecasters first predicted how they would feel following a positive or negative impacting event (winning funds for car expenses or having to pay for car repairs). Forecasters and backcasters then rated the extent to which they thought about the effects of elapsed time and the occurrence of future events on their feelings, using a measure adapted from research by Igou (2004) and Wilson and his colleagues (2000). We expected that backcasters would think about future period information more than forecasters, but that backcasters and forecasters would think about elapsed time information to a similar extent.

\section{Method}

Participants. Participants were students who were recruited in a public place on the University of Minnesota campus to complete a questionnaire in exchange for candy. 
Of the 99 participants who completed the questionnaire, 49 were female and 50 were male. The participants' mean age was 20.6 years $(\mathrm{SD}=2.17$ years).

Procedure. Participants who agreed to complete a questionnaire were randomly assigned to a predictor condition (forecaster or backcaster) and an impacting event condition (positive or negative). The questionnaire was similar to the one used in study 1a. Participants first answered a baseline mood question, followed by a question that varied by experimental condition, followed by the hedonic prediction. Each question was presented on a new page. For forecasters, the second question read: "Imagine that you bought a used car from a dealer a few months ago. Later today you find out from the dealer that you have won $\$ 1,000$ in a draw for recent customers to spend on any expenses for your car (to use when and where you want). [Later today your car breaks down and you find out that the repair, which will take a couple of days, is going to cost you $\$ 1,000$.] How will you feel in general at the moment you find that out?" For backcasters, the second question read "How will you feel in general 1 week from today?" Third and finally, all participants made a prediction of their future feelings given the occurrence of the impacting event: "Imagine that you bought a used car from a dealer a few months ago. Later today you find out from the dealer that you have won $\$ 1,000$ in a draw for recent customers to spend on any expenses for your car (to use when and where you want). [Later today your car breaks down and you find out that the repair, which will take a couple of days, is going to cost you $\$ 1,000$.] How will you feel in general 1 week from today?" Participants responded to all questions using a 9-point scale $(1=$ very unhappy, $5=$ neither happy nor unhappy, $9=$ very happy).

Next, participants rated the extent to which the thoughts they had while making the hedonic prediction were best described by each of seven statements. Five of these statements described changes in feelings over time, with the first four adapted from Igou (2004). The statements were (a) no feelings last long, $(b)$ happiness and unhappiness are transitory, $(c)$ some experiences have a lasting influence on a person, $(d)$ no experience is so bad that I would not be able to accept it, and $(e)$ experiences like this have a big impact on my feelings. The final two statements described the effects of future events and were adapted from Wilson et al. (2000). They were $(f)$ other things will be happening over the coming week that will also influence my feelings and ( $g$ ) other things will be happening over the coming week that will distract me from thinking about this experience. Participants used a 9-point scale $(1=$ not thinking this at all, $9=$ thinking this very much) to respond.

\section{Results}

Predictions. Participants' hedonic predictions were submitted to a 2 (predictor: forecaster or backcaster) $\times 2$ (impacting event: positive or negative) ANCOVA with responses to the baseline question used as a covariate.
The analysis revealed a main effect of impacting event $(F(1,94)=51.51, p<.001$, eta $=.59)$, which was qualified by a predictor $\times$ impacting event interaction $(F(1,94)=5.47, p=.02$, eta $=.25)$. As figure 1 shows, backcasters predicted a greater influence of the impacting event $\left(M_{\text {pos. }}=7.28, M_{\text {neg. }}=4.46\right)$ than did forecasters $\left(M_{\text {pos. }}=6.77, M_{\text {neg. }}=5.16\right)$. Separate ANCOVAs revealed that the difference between backcasters and forecasters occurred to some degree for both the positive event $(F(1,48)=2.67, p=.11$, eta $=.23)$ and the negative event $(F(1,45)=3.52, p=.07$, eta $=.27)$.

Thinking about the Effect of Elapsed Time and the Future Period. The statements that were relevant to both positive and negative events (i.e., items $a, b, c$, and $e$ ) showed a weak but consistent pattern in means for both positive and negative events, such that forecasters thought more about feelings dissipating (items $a$ and $b$ ) and less about feelings enduring (items $c$ and $e$ ) than did backcasters. Means for these items (collapsed across positive and negative events) were, for forecasters, $M_{a}=4.71, M_{b}=4.84$, $M_{c}=5.98$, and $M_{e}=4.71$; for backcasters, $M_{a}=4.33$, $M_{b}=4.54, M_{c}=6.52$, and $M_{e}=5.44$. (Item $d$ was only relevant for negative events and showed this pattern for those events only.) The two dissipation items were moderately correlated, as were the two endurance items (median correlations across conditions: $r_{\text {diss. }}=.33 ; r_{\text {end. }}=.37$ ), but correlations between dissipation and endurance items were low and positive (median $r=.15$ ). That is, people who were thinking more about their feelings dissipating were not necessarily thinking less about their feelings enduring; rather, those thoughts were relatively independent. As such, we constructed separate "feelings dissipate" and "feelings endure" variables by averaging the relevant items. A 2 (predictor: forecaster or backcaster) $\times 2$ (impacting event: positive or negative) ANOVA on each of these variables revealed only a marginally significant effect of predictor for the feelings endure variable $(F(1,95)=2.91, p=.09$,

\section{FIGURE 1}

PREDICTED FUTURE HAPPINESS FOR IMPACTING EVENTS IN STUDY 1B

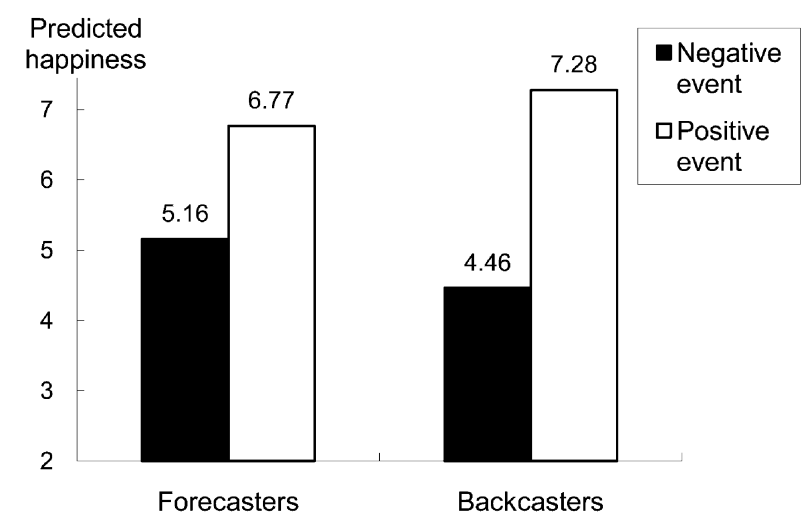


eta $=.17)$, such that backcasters thought more about their feelings enduring than did forecasters (backcasters: $M_{\text {diss. }}=4.44, \quad M_{\text {end. }}=5.98 ;$ forecasters: $M_{\text {diss. }}=4.77$, $M_{\text {end. }}=5.34$; see fig. 2.$)$

The same analysis for each of the items relevant to future period revealed only a significant effect of predictor for item $f$ ("Other things will be happening over the coming week that will also influence my feelings"; $F(1,95)=4.06$, $p=.05$, eta $=.20)$, such that backcasters thought more about this effect of future events $(M=6.56)$ than did forecasters $(M=5.71)$. Means for item $g$ ("Other things will be happening over the coming week that will distract me from thinking about this experience") were $M_{\text {back. }}=6.22$ and $M_{\text {fore. }}=5.90$ (see fig. 2 ).

\section{Discussion}

Backcasters were once again more likely than forecasters to predict that an event would have considerable hedonic impact in a future period, making more extreme hedonic predictions on average. This was generally the case for both positive and negative events. Backcasters thought more about the influence of future events on their feelings and (to some degree) more about their feelings enduring over time than did forecasters. However, backcasters and forecasters were similar in the extent to which they thought about their feelings dissipating over time and about the distracting effects of future events.

The relative independence of the endurance and dissipation variables was surprising. It may be that the endurance variable in part represents thinking about the impacting event, while the dissipation variable more closely represents thinking about elapsed time. If so, these results are consistent with study 1a, which found that backcasters focus more on the impacting event when making their impact predictions than do forecasters.

\section{STUDY 2}

In studies $1 \mathrm{a}$ and $1 \mathrm{~b}$, we found that backcasters make more extreme hedonic predictions than forecasters, and they differ in the information they consider when making their predictions. Backcasters think more than forecasters about impacting event and future period information, while both types of predictors think to a similar extent about elapsed time information (in its effect on dissipation of feelings). In both these studies, the extent of thinking about impacting event, elapsed time, and future period information is measured, not manipulated. This makes it difficult to separate the influences of these three types of information, leading to ambiguity in interpretation of their effects on predictions. This is especially the case as these types of information may be naturally confounded in hedonic predictions. For example, people usually, and sometimes incorrectly, expect more intense events to affect their feelings for longer (Gilbert et al. 2004), confounding the effects of impacting event and elapsed time information. We address these issues in study 2 .
FIGURE 2

PREDICTORS' THINKING ABOUT THE EFFECTS OF ELAPSED TIME AND FUTURE PERIOD IN STUDY 1B

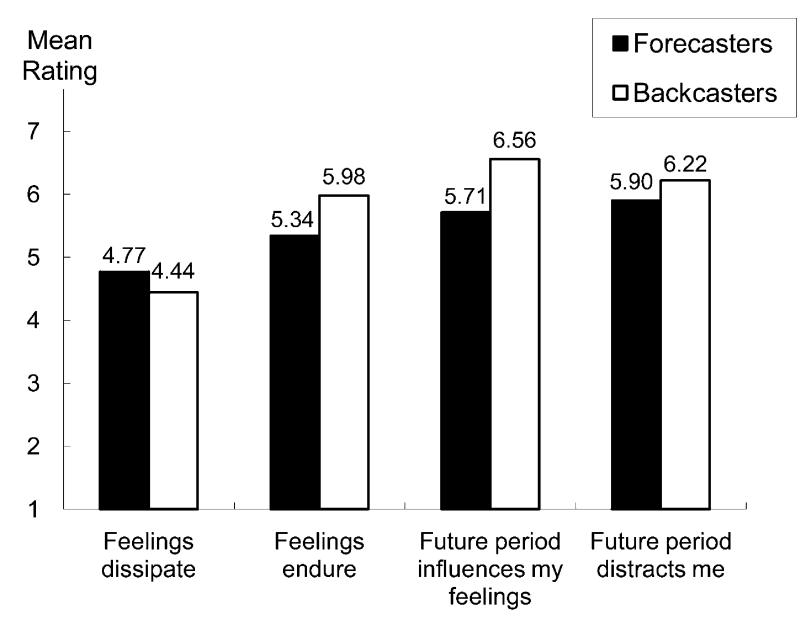

In this study, we used a method similar to the one used in the previous studies. Specifically, backcasters and forecasters were asked to predict how they would feel in a future period given the occurrence of a positive or negative impacting event (performing well or poorly on an exam). In addition, we manipulated $(a)$ the elapsed time between the impacting event and future period and $(b)$ the valence of the future period, to examine the separate effects of these three types of information on hedonic predictions. Consistent with our findings in studies $1 \mathrm{a}$ and $1 \mathrm{~b}$, we expected that backcasters would be more influenced than forecasters by information about the impacting event and the future period and that they would be similarly influenced by elapsed time.

\section{Method}

Participants. Participants were students who were recruited in a public place on the Harvard University campus to complete a questionnaire in exchange for candy. Of the 239 participants, 119 were female and 120 were male. The participants' mean age was 20.2 years $(\mathrm{SD}=1.3$ years $)$.

Procedure. Participants were randomly assigned to one of 16 experimental conditions that included a predictor condition (forecaster or backcaster). We also manipulated the valence of the impacting event (positive or negative), the valence of the future period (positive or negative), and the elapsed time (long or short) between the impacting event and the future period. We manipulated the valence of the impacting event by using good or bad performance on an exam as the impacting event. We manipulated the valence of the future period by having it fall on a Saturday or a Monday. Research has shown that people expect to feel worse on Mondays than on any other day of the week (Stone et al. 1985). Finally, we manipulated elapsed time by having 
FIGURE 3

PREDICTED FUTURE HAPPINESS AFTER DIFFERENT ELAPSED TIMES FOR IMPACTING EVENTS IN STUDY 2

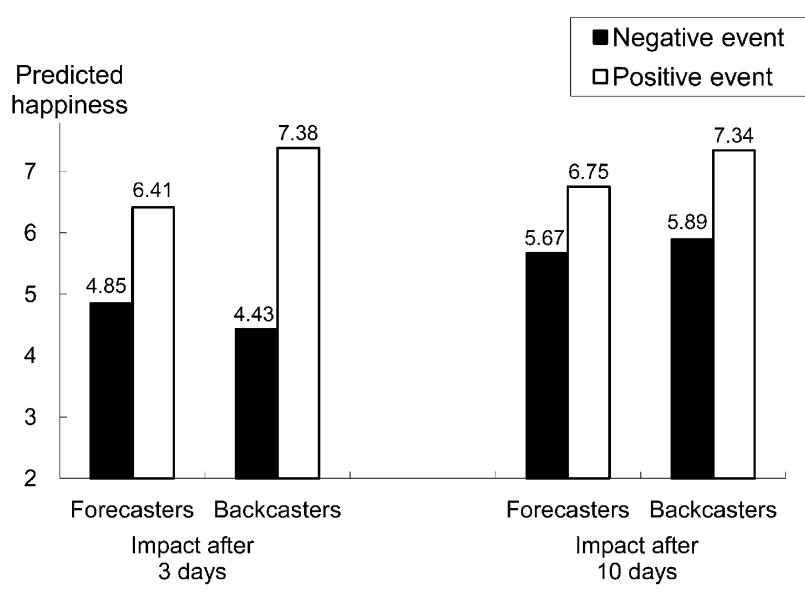

the future period occur 3 days or 10 days after the impacting event. In this study, we used two baseline mood questions: one that asked participants to rate their current mood and one that asked them to rate their usual mood.

The question order was similar to previous studies. For example, a forecaster in the positive impacting event/positive future period/short elapsed time condition answered the following four questions: (1a) "How do you feel in general right now?" (1b) "How do you usually feel in general?" (2) "Imagine you find out on Wednesday, March 7th that your score on the last test you took is much better than you expected. How will you feel in general at the moment you find that out?" (3) "Imagine you find out on Wednesday, March 7th that your score on the last test you took is much better than you expected. How will you feel in general on Saturday, March 10th?" For backcasters in the same condition, question 2 was replaced with "How will you feel in general on Saturday, March 10th?" For the negative event conditions, "better" was replaced with "worse," and for the Monday conditions, "Wednesday, March 7th" was replaced with "Friday, March 9th" so that the elapsed time was still 3 or 10 days for the two Monday dates. Questions 1a and $1 \mathrm{~b}$ were presented on the first page of the booklet, with questions 2 and 3 each on subsequent pages.

\section{Results}

Participants' hedonic predictions were submitted to a 2 (predictor: forecaster or backcaster) $\times 2$ (impacting event: positive or negative) $\times 2$ (future period: positive or negative) $\times 2$ (elapsed time: short or long) ANCOVA with responses to the baseline questions used as covariates.

The analysis revealed interactions consistent with our results in studies 1a and $1 \mathrm{~b}$. First, as shown in figure 3, the predictor $\times$ impacting event interaction was significant $(F(1,221)=4.71, p=.03$, eta $=.14)$. Just as in studies 1a and $1 \mathrm{~b}$, backcasters predicted a greater impact of the event than did forecasters (collapsing across other conditions, backcasters: $M_{\text {pos. }}=7.36, M_{\text {neg. }}=5.14$; forecasters: $\left.M_{\text {pos. }}=6.58, M_{\text {neg. }}=5.19\right)$. Second, the analysis also revealed an impacting event $\times$ elapsed time interaction $(F(1,221)=8.67, p=.004$, eta $=.19)$, such that both backcasters and forecasters expected the event to have less impact after a longer time had elapsed. The predictor $x$ impacting event $\times$ elapsed time interaction was not significant $(p=.60)$, indicating that both groups were influenced to a similar extent by elapsed time.

As figure 4 shows, the analysis also revealed a predictor $\times$ future period interaction $(F(1,221)=7.65, p=.006$, eta $=.18)$, such that backcasters expected to be happier on a Saturday than on a Monday (for backcasters, collapsing across other conditions: $M_{\text {Mon. }}=5.95, M_{\text {Sat. }}=6.61$; $F(1,109)=4.64, p=.03$, eta $=.20)$, but forecasters did $\operatorname{not}\left(M_{\text {Mon. }}=6.03, M_{\text {Sat. }}=5.79 ; p=.12\right)$. In other words, only backcasters considered the future period when predicting their happiness following an impacting event. No other interactions were significant ( $p$ 's $>.25$ ).

Consistent with study $1 \mathrm{~b}$, we also examined the results separately for positive and negative impacting events. Separate ANCOVAs revealed that the effects of elapsed time were only significant for the negative event $(F(1,109)=$ 17.36, $p<.001$, eta $=.37$ ), suggesting that all predictors expected the hedonic impact of the positive event to have largely dissipated after 3 days but that they expected the hedonic impact of the negative event to endure beyond 3 days (though with considerably less impact after 10 days). It may be that the students in this study expect that getting a worse score than they expected in the class would be a more affectively intense experience than getting a better score than they expected and thus would have a more enduring impact on their feelings. Alternatively, this asymmetry in impact of positive and negative events is also consistent with some previous work showing that people expect

\section{FIGURE 4}

PREDICTED FUTURE HAPPINESS FOR DIFFERENT FUTURE PERIODS FOR IMPACTING EVENTS IN STUDY 2

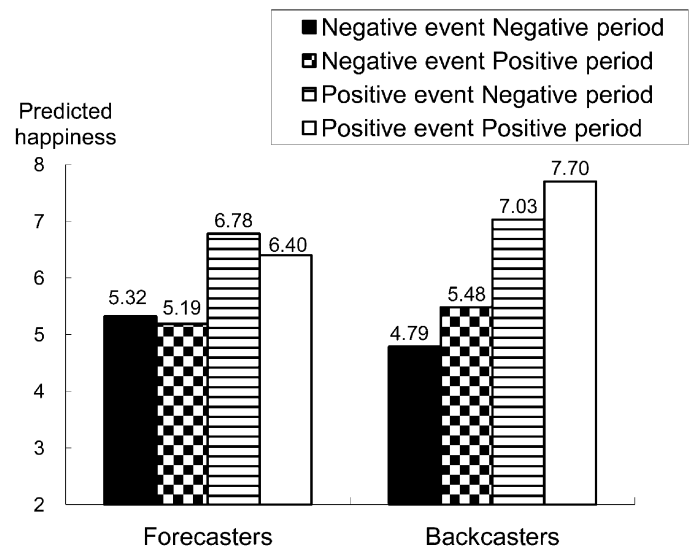


the impact of negative events to endure longer than those of positive events (Kermer et al. 2006).

The predictor $\times$ future period interaction was significant or marginally significant for both positive and negative events $(F$ 's $>3.18, p$ 's $<.08$, eta's $>.17)$. This result, in conjunction with the finding that neither the predictor $\times$ future period $\times$ impacting event interaction nor the future period $x$ impacting event interaction for backcasters or forecasters alone were significant $(F$ 's $<1)$, suggests that the effect of the valence of the future period was similar for both positive and negative events. In other words, for backcasters the valence of the future period had an additive effect on hedonic predictions, such that they predicted greater happiness on Saturday and less happiness on Monday, whereas for forecasters the valence of the future period had no significant effect.

\section{Discussion}

Backcasters were more influenced by the impacting event and the future period than forecasters were: backcasters made more extreme hedonic predictions on average for both positive and negative events and made more positive hedonic predictions for a positive future period (a Saturday) than a negative future period (a Monday), but forecasters did not. The influence of elapsed time information was similar for both groups: that is, both groups expected the hedonic impact of the event to dissipate over time (their impact predictions after 10 days were less extreme than after 3 days), and this expected dissipation was similar for backcasters and forecasters. These results correspond closely to the thought-listing and self-reported ratings in studies 1a and $1 \mathrm{~b}$, which, taken together, suggested that backcasters consider and are influenced by the impacting event and the future period more than forecasters and that both consider elapsed time and are similarly influenced by it.

The results of the current study also imply that backcasters' more extreme hedonic predictions are caused by their greater consideration of impacting event information relative to forecasters, not by their consideration of future period or elapsed time information. Backcasters do consider future period information more than forecasters, and considering a positive future period causes them to make more positive (more extreme) hedonic predictions for positive events. However, it also causes backcasters to make more positive (less extreme) hedonic predictions for negative events. Also, while elapsed time information influences both backcasters and forecasters, leading them make more moderate predictions, it influences both to a similar extent.

\section{STUDY 3}

While the lack of difference in consideration of elapsed time information implies that it is backcasters' greater consideration of impacting information that leads them to make more extreme hedonic predictions than forecasters, we sought to confirm this in study 3 by manipulating impacting event information (both valence and intensity) while holding elapsed time constant. People have little difficulty predicting the valence of the affect (negative or positive) they will feel following an event, but they have trouble predicting the intensity of that affect (Wilson and Gilbert 2003). By using impacting events that differ in intensity as well as valence, we hoped to create a more stringent test of predictors' use of impacting event information. If backcasters make more extreme hedonic predictions because they consider impact event information more than forecasters do, then we would expect backcasters to be more influenced than forecasters by both the intensity and valence manipulations.

In addition, in study 3 we included a group of "unguided predictors" - that is, participants who were not guided to make backcasts or forecasts - to determine whether their hedonic predictions were more like those of backcasters or forecasters. Therefore, in this study, three predictor groups (backcasters, forecasters, and unguideds) predicted how they would feel 2 weeks after an extremely positive, moderately positive, moderately negative, or extremely negative event.

\section{Method}

Participants. Participants were students who were recruited in a public place on the University of Minnesota campus to complete a questionnaire in exchange for candy. Of the 181 participants who completed the questionnaire, 100 were female, 77 were male, and four did not specify their gender. The participants' mean age was 22.5 years $(\mathrm{SD}=5.2$ years $)$.

Procedure. Participants were randomly assigned to one of 12 experiment conditions that included three predictor conditions (backcaster, forecaster, or unguided). We also manipulated impacting event valence (positive or negative) and impacting event intensity (moderate or extreme) by using performance on an exam as the impacting event. The questions and order were similar to those used in study 2 , except that $(a)$ participants' hedonic predictions concerned either a moderate impacting event ("You find out later today that your score on the last midterm you took is much higher [lower] than you expected") or an extreme impacting event ("You find out later today that your score on the last midterm you took is the highest [lowest] in the class"), (b) we included an unguided condition for which question 2 was omitted, and $(c)$ participants were asked to predict their feelings " 2 weeks from today" rather than on a specific date.

So, for example, a forecaster in the positive/extreme condition answered the following four questions: (1a) "How do you feel in general right now?" (1b) "How do you usually feel in general?" (2) "Imagine you find out later today that your score on the last midterm you took is the highest in the class. How will you feel in general at the moment you find that out?" (3) Imagine you find out later today that your score on the last midterm you took is the highest in the class. How will you feel in general 2 weeks from today?" For backcasters in the same condition, question 2 was replaced with "How will you feel in general 2 weeks from today?" For unguideds, question 2 was omitted. 


\section{Results}

Forecasters and Backcasters. Participants' hedonic predictions were submitted to a 2 (predictor: forecaster or backcaster) $\times 2$ (impacting event valence: positive or negative) $\times 2$ (impacting event intensity: moderate or extreme) ANCOVA with responses to the baseline questions used as covariates. The analysis revealed a main effect of impacting event valence $(F(1,111)=37.69, p<.001$, eta $=.50)$, which was qualified by a predictor $\times$ impacting event valence interaction $(F(1,111)=7.04, p=.009$, eta $=.24)$. Backcasters were once again more likely than forecasters to predict that the impacting event would have a considerable impact (collapsing across intensity conditions, for backcasters: $M_{\text {pos. }}=7.33, M_{\text {neg. }}=5.32$; for forecasters: $M_{\text {pos. }}=$ $6.65, M_{\text {neg. }}=5.69$; see fig. 5). Separate ANCOVAs revealed that this difference in backcasters' and forecasters' predictions occurred for both the positive and negative events (positive event: $F(1,55)=3.78, p=.06$, eta $=.25$; negative event: $F(1,54)=2.91, p=.09$, eta $=.23$ ).

There was also a marginal impacting event valence $x$ impacting event intensity interaction $(F(1,111)=3.35$, $p=.07$, eta $=.17$ ), which was qualified by a predictor $\times$ impacting event valence $\times$ impacting event intensity interaction $(F(1,111)=4.62, p=.03$, eta $=.20)$. Separate ANCOVAs for backcasters and forecasters illuminated the nature of this interaction: the impacting event valence $x$ impacting event intensity interaction was significant for backcasters $(F(1,55)=6.61, p=.01$, eta $=.33)$ but not for forecasters $(p=.74)$. In other words, backcasters' predictions were more strongly influenced by information about the valence and intensity of the impacting event than were forecasters' predictions (see fig. 5).

Furthermore, a 2 (impacting event valence) $\times 2$ (impacting event intensity) ANCOVA on forecasters' ratings of the initial impact of the event (i.e., question 2) also revealed no effects of intensity ( $F$ 's $<1)$. In short, forecasters' ratings of the initial impact and the future impact of the impacting event were not influenced by information about the intensity of that event. This null finding is unlikely to be explained as a ceiling or floor effect. For example, forecasters' standard deviations for their ratings of the initial impact and the future impact of extreme events were similar to or larger than those for the moderate events; forecasters' mean initial impact rating for positive events was slightly higher for the moderate event than for the extreme event; and their initial impact rating for the negative events was significantly higher than 1 , the lowest point on the scale $\left(M_{\text {ext. }}=2.86, M_{\text {mod. }}=3.00\right)$.

Unguideds. As shown in figure 5, unguided participants resembled backcasters more than forecasters, both in terms of their hedonic predictions and in the influence of information about the intensity of the impacting events. A focused ANCOVA comparing unguideds with forecasters revealed the same interaction found when backcasters were compared with forecasters (predictor $\times$ impacting event valence: $F(1,110)=4.18, p=.04$, eta $=.19$; predictor
FIGURE 5

PREDICTED FUTURE HAPPINESS FOR IMPACTING EVENTS IN STUDY 3

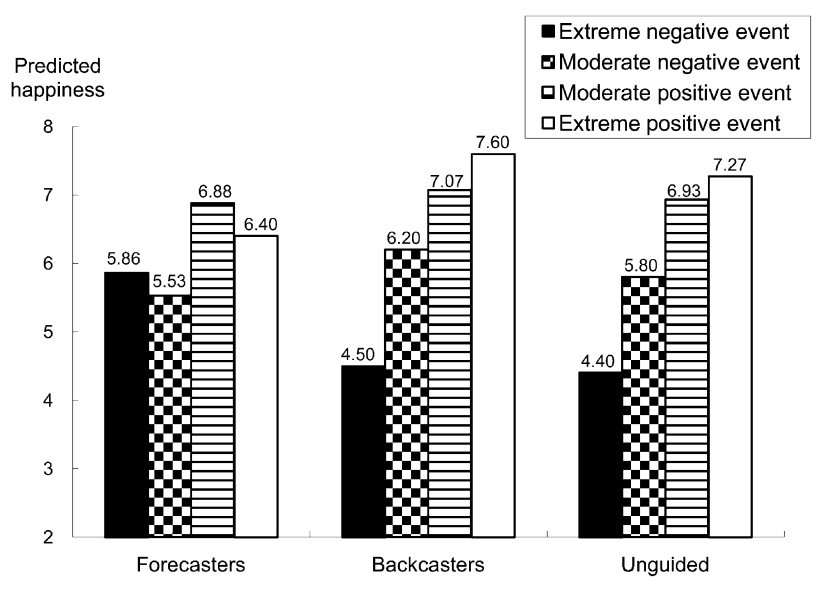

$\times$ impacting event valence $\times$ impacting event intensity: $F(1,110)=5.02, p=.03$, eta $=.21)$. Furthermore, these interactions were not significant in a similar analysis comparing unguideds with backcasters $(p$ 's $>.53)$. Also as for backcasters, a focused impacting event valence $\times$ impacting event intensity ANCOVA on the hedonic predictions of unguideds alone revealed a significant impacting event valence $\times$ impacting event intensity interaction $(F(1,54)=6.34$, $p=.01$, eta $=.32$ ), suggesting that unguideds' predictions were also influenced by information about both the valence and intensity of the impacting events.

\section{Discussion}

Backcasters were once again more likely than forecasters to predict that an event would have a considerable hedonic impact in a future period, making more extreme hedonic predictions on average. Backcasters were also more influenced than forecasters by information about the valence and intensity of the future event. This result is consistent with study 1a, in which backcasters thought more exclusively than forecasters about the impacting event. Unguided predictors were similar to backcasters in both the predictions they made and in the influence of impacting event information. While the lack of differences observed between backcasters and unguided predictors does not prove that unguided predictors were backcasting, the differences between forecasters and unguided predictors at least suggests that the latter were not forecasting.

In addition, the lack of an effect of the intensity of the impacting event on forecasters is consistent with our argument, following the results of studies $1 \mathrm{~b}$ and 2 , that a differential use of elapsed time information by forecasters and backcasters is unlikely to account for backcasters' more extreme hedonic predictions. Given the likely confound of 
intensity and duration of feelings in hedonic prediction, it is conceivable that the same elapsed time ( 2 weeks in this study) would have a different effect on hedonic predictions for extreme and moderate events, as the effects of extreme events may be expected to endure longer. Therefore, backcasters' more extreme hedonic predictions could be explained if forecasters are more influenced by elapsed time information than backcasters. If this were the case in the present study, forecasters should have shown a greater influence of the intensity and valence manipulations than backcasters. Instead, backcasters showed a greater influence of these manipulations than forecasters, which reinforces our suggestion that it is the differential influence of impacting information that causes backcasters to make more extreme hedonic predictions than forecasters.

\section{GENERAL DISCUSSION}

The present research compared two methods by which consumers may predict how they will feel if an impacting event occurs: backcasting (whereby consumers first consider their feelings in a future period and then consider how those feelings might be different if the impacting event occurred) and forecasting (whereby consumers first consider how they would feel at the time an impacting event occurs and then consider how those feelings might change in a future period). We guided participants to make predictions by one of these methods so that we could determine whether the methods produced similar or different predictions. We hypothesized that backcasters and forecasters would differ in the extent to which they consider the information relevant to hedonic impact predictions, leading them to make different predictions. Specifically, we hypothesized that backcasters would consider information about the impacting event and the future time period more than forecasters do, whereas they would consider information about the elapsed time between the impacting event and a future period to a similar extent. Finally, we hypothesized that the relatively powerful influence of impacting event information on hedonic predictions would lead backcasters to make more extreme hedonic impact predictions than forecasters.

What have we learned? The data across four studies consistently supported our hypotheses. First, in all four studies, backcasters and forecasters made different predictions when provided with the same information; specifically, backcasters were more likely than forecasters to predict that an event would have considerable hedonic impact in the future, making more extreme hedonic predictions on average. Second, backcasters and forecasters considered different kinds of information to different extents. Specifically, backcasters appeared to be more likely than forecasters to consider the nature of the impacting event and their feelings in a future period and no less likely to consider the influence of elapsed time. Third, the difference in backcasters' and forecasters' predictions was caused primarily by the difference in their consideration of the impacting event.

These results contribute to the growing literature on anticipated affect in consumer behavior by examining the ef- fects on hedonic predictions of different prediction approaches. Given the demonstrated influence of anticipated affect on choice and preference, behavioral intentions, and consumer satisfaction (Patrick, MacInnis, and Park 2007; Richard et al. 1996; Shiv and Huber 2000; Simonson 1992), these results will be of interest to both researchers and practitioners in consumer behavior.

\section{Why Do Backcasters Predict a Greater Impact of Events on Their Future Feelings than Forecasters?}

Backcasters make more extreme hedonic predictions primarily because they consider the impacting information to a greater extent than forecasters do. They described thinking more exclusively about the impacting event than forecasters did (study 1a), and variation in impacting event information influenced backcasters' predictions more than it influenced forecasters' predictions (studies 2 and 3).

A potential alternative (or additional) explanation, that backcasters and forecasters make different impact predictions because they consider elapsed time information to a different extent, was not supported. While they made different hedonic predictions, backcasters and forecasters did not differ in the extent to which they thought about the dissipation of their feelings over time (study 1b), and while both backcasters and forecasters moderated their predictions with elapsed time after an impacting event, they did so to the same degree (study 2).

Backcasters consider the future period more than forecasters do. They thought more about the influence of future events on their feelings (study 1b) and adjusted their hedonic predictions accordingly, so their predictions were more positive for a positive future period and more negative for a negative future period (study 3 ). This additive effect of the valence of a future period is consistent with some research on how feelings for different experiences are combined (Linville and Fischer 1991). However, it contrasts with other research in which considering a future period had a diluting effect, moderating hedonic predictions (Wilson et al. 2000). Whether considering the future period has an additive or a diluting effect probably depends on how that future period is considered. In the Wilson et al. (2000) studies, before making their hedonic predictions for the impact of an event in a future period, participants first estimated the time they would spend on 10 or more activities in that future period (e.g., studying, socializing with friends). Considering the future period in this way prompted participants to think about the diverting effects of those future activities, which caused them to moderate their hedonic predictions. This moderation occurred when participants considered either affectively neutral or valenced activities. In contrast, in the current research, participants were asked to estimate their feelings in a positively or negatively valenced future period (a Saturday or a Monday) before making their hedonic predictions, presumably focusing their attention on affective information about the future period. This caused them to add their positive or negative feelings for that future period 
to their hedonic predictions. While considering a future period can have either an additive effect (as in our studies) or a diluting effect (as in the Wilson et al. studies) on hedonic predictions, neither effect can account for backcasters' more extreme hedonic predictions for both positive and negative impacting events.

These differences in the information backcasters and forecasters consider and the predictions they make suggest that simply changing the order in which consumers think about a potential consumption event and an upcoming future time period can markedly change their expectations about the affective consequences of the event. Just as we can change performance and other consumer expectations using communications (Crosby and Taylor 1981), marketers should be able to change consumers' hedonic expectations simply by prompting consumers to think ahead to the future before considering a consumption event. For example, an advertisement in the midst of a snowy winter might read: "How are you going to be feeling in frigid February? Imagine you take a sun-filled Caribbean cruise next week. Now imagine how you will feel in February. Help yourself through the winter . . . book a cruise today." Consumers reading this advertisement should expect the cruise to make them feel happier in February, more so than should consumers who read an advertisement that prompts them to think first about the cruise before they consider how it will make them feel later.

But why do backcasters and forecasters consider different information to different extents? The current work demonstrates order effects for hedonic predictions, where presenting relevant information in different orders results in different hedonic predictions. As such, it adds to other consumer research demonstrating order or serial position effects (Büyükkurt 1986; Gurhan-Canli, Mick, and Brucks 2003; Haugtvedt and Wegener 1994; Hovland 1957; Jedidi and Jacoby 1997; Kardes and Herr 1990; Miller and Campbell 1959; Pieters and Bijmolt 1997). However, unlike many other results demonstrating serial position effects, a simple explanation based only on the primacy or recency of the information presented is inadequate to explain the current results.

First, consider a primacy explanation: that consumers will simply weigh information presented first more heavily. However, in our studies, the information first encountered by forecasters and backcasters (the impacting event and future period respectively) is weighted relatively heavily only by backcasters. Second, consider a recency explanation: that consumers will simply weight information presented last more heavily. However, here, the information encountered last by forecasters and backcasters (future period and elapsed time for forecasters; impacting event and elapsed time for backcasters) is again weighted heavily only by backcasters (future period) or is weighted similarly by both (elapsed time). So neither a simple primacy nor recency explanation is sufficient to explain the results we obtain.

Relative to backcasters, forecasters neglect the future period in their impact predictions. Consistent with focalism research (Wilson et al. 2000), we have suggested that backcasters' greater consideration of future period information occurs because they are compelled to consider their feelings in a future period before they make their hedonic predictions. This difference in consideration of future period information may also be due to forecasters using a correction process to make their hedonic predictions, as suggested by some earlier research in hedonic prediction (Gilbert, Gill, and Wilson 2002). In that research, participants made impact predictions by first considering their response to an event (eating spaghetti) before correcting for the circumstances (eating it in the morning or evening). Such correction tends to be insufficient (Epley and Gilovich 2001; Gilbert 2002; Tversky and Kahneman 1974) and contributed to the impact bias observed in those studies. Similarly, in our studies, forecasters are asked to first consider the impacting event and then consider the circumstances (the future period and the elapsed time). Insufficient correction, as seen in the spaghetti studies, could also help explain their relative neglect of future period information here.

The fact that backcasters show a greater influence of the information they consider second (i.e., the impacting event information) suggests that a similar correction account of backcasting is unlikely. We have suggested an alternative possibility for the process involved in backcasting, based on how people make comparisons (Tversky 1977; Tversky and Gati 1978). That is, when comparing a future following the occurrence of an impacting event (the subject of the comparison) against a future where the event has not occurred (the referent of the comparison), a backcaster weights the unique aspects of the subject of the comparison (e.g., how seeing the Red Sox lose today will make her feel) more heavily than the referent (e.g., how she will feel on her birthday in a few days). As a result, the impacting event has a powerful influence on backcasters' predictions.

We can apply a similar account to our unguided predictors (in study 3) who compare a future following the occurrence of an impacting event (the subject of the comparison) against their baseline mood (what they estimate first and so the referent of the comparison). Like backcasters, these unguided predictors show a powerful influence of the impacting event information, and they make similar hedonic predictions to backcasters. While this account of backcasting (and of our unguided predictors) fits our results quite well, additional research is needed to determine whether this account of backcasting holds true.

\section{In What Contexts Will Consumers Use Backcasting and Forecasting?}

In our studies, we explicitly asked participants to make hedonic predictions. But in what contexts might consumers spontaneously use forecasting or backcasting to make them? It seems reasonable to suspect that consumers will naturally begin most hedonic prediction tasks by contemplating the temporal period in which they are primarily interested. For example, when making future plans, a consumer probably 
begins by simulating the future ("I'm looking forward to my birthday in a few days") and only then considers how current events might alter those simulations ("And if I see the Red Sox lose tomorrow I might still feel upset on my birthday"). That is, she will probably backcast. On the other hand, when contemplating or choosing a course of immediate action, such as when choosing between current options ("I wonder if should go to the Red Sox game tonight or watch that new comedy instead"), a consumer would probably begin by simulating the consumption event ("It would be awful if the Red Sox lost") and then consider how those feelings will be changed by the passage of time ("But I should feel better by my birthday"). That is, she will probably forecast.

Similarly, people may use backcasting and forecasting when regulating their feelings in future and current periods, respectively. Consumers frequently use consumption events to regulate their mood-for example, buying gifts for themselves or listening to music to improve their mood (Chen, Zhou, and Bryant 2007; Gould 1997). Research shows that mood regulation can be anticipatory, used to cause a particular mood for a particular situation, or reactive, used to alter an existing mood (Erber, Wegner, and Therriault 1996; Gross 1998). A consumer who wants to achieve a particular mood in a future situation will probably first think about the future situation and the mood he would like to achieve and then consider the impact of the consumption event on his feelings (also suggested in MacInnis et al. [2006]). That is, she will probably backcast. On the other hand, a consumer who wants to change an existing mood will probably first consider the impact of the consumption event on her feelings before considering how those feelings might change over time. That is, she will probably forecast.

\section{Will Backcasting or Forecasting Lead to More Accurate Predictions?}

We did not measure experienced feelings in these studies and so cannot know whether our predictors were accurate, although the impact bias has been obtained for situations very similar to those used in the current research (e.g., the use of exams as stimuli in Buehler and McFarland [2001]), where predictors overestimate the impact of events on their feelings (Wilson and Gilbert 2003).

Future research is needed to determine whether backcasting or forecasting leads to more accurate predictions in general. But even now it is not difficult to speculate about the circumstances under which each may prove superior. For example, because backcasting forces consideration of feelings in a future period while forecasting results in neglect of those feelings, backcasting is likely to be the superior method when the future period evokes strong feelings. A car enthusiast who purchases a vintage car may be very excited about her purchase but may use forecasting to predict she will be less excited in a month. But if that date in a month is, in fact, the day of her first car rally, she may feel more excited in a month than forecasting led her to expect.
On the other hand, backcasting can foster errors by encouraging consumers to heavily weigh impacting events that may in fact be forgotten by the time the future arrives. A taxpayer may initially expect to be happy at Christmas until he considers how unhappy he will be next week on tax day, at which point he may revise his expectations about Christmas ("I'll have to give everyone expensive presents when I can barely afford bus fare!"). But April memories are likely to fade by December, and this taxpayer will probably feel much better at Christmas than backcasting led him to expect. Thus, it seems likely that each strategy will have its own domain of applicability and its own domain of susceptibility to error.

\section{REFERENCES}

Buehler, Roger and Cathy McFarland (2001), "Intensity Bias in Affective Forecasting: The Role of Temporal Focus," Personality and Social Psychology Bulletin, 27 (11), 1480-93.

Büyükkurt, B. Kemal (1986), "Integration of Serially Sampled Price Information: Modeling and Some Findings," Journal of Consumer Research, 13 (3), 357-73.

Chen, Lei, Shuhua Zhou, and Jennings Bryant (2007), "Temporal Changes in Mood Repair through Music Consumption: Effects of Mood, Mood Salience, and Individual Differences," Media Psychology, 9 (3), 695-713.

Coughlan, Richard and Terry Connolly (2001), "Predicting Affective Responses to Unexpected Outcomes," Organizational Behavior and Human Decision Processes, 85 (2), 211-25.

Crosby, Lawrence A. and James R. Taylor (1981), "Effects of Consumer Information and Education on Cognition and Choice," Journal of Consumer Research, 8 (1), 43-56.

Dunn, Elizabeth W., Timothy D. Wilson, and Daniel T. Gilbert (2003), "Location, Location, Location: The Misprediction of Satisfaction in Housing Lotteries," Personality and Social Psychology Bulletin, 29 (11), 1421-32.

Dunning, David and Mary Parpal (1989), "Mental Addition versus Subtraction in Counterfactual Reasoning: On Assessing the Impact of Personal Actions and Life Events," Journal of Personality and Social Psychology, 57 (1), 5-15.

Epley, Nicholas and Thomas Gilovich (2001), "Putting Adjustment Back in the Anchoring and Adjustment Heuristic: Differential Processing of Self-Generated and Experimenter-Provided Anchors," Psychological Science, 12 (September), 391-96.

Erber, Ralph, Daniel M. Wegner, and Nicole Therriault (1996), "On Being Cool and Collected: Mood Regulation in Anticipation of Social Interaction," Journal of Personality and Social Psychology, 70 (4), 757-66.

Finkenauer, Catrin, Marcello Gallucci, Wilco W. van Dijk, and Monique Pollmann (2007), "Investigating the Role of Time in Affective Forecasting: Temporal Influences on Forecasting Accuracy," Personality and Social Psychology Bulletin, 33 (8), 1152-66.

Gaunt, Ruth, Denis Sindic, and Jacques-Philippe Leyens (2005), "Intergroup Relations in Soccer Finals: People's Forecasts of the Duration of Emotional Reactions of In-Group and OutGroup Soccer Fans," Journal of Social Psychology, 145 (2), 117-26.

Gilbert, Daniel T. (2002), "Inferential Correction," in Heuristics and Biases: The Psychology of Intuitive Judgment, ed. 
Thomas Gilovich, Dale W. Griffin, and Daniel Kahneman, Cambridge: Cambridge University Press, 167-84.

Gilbert, Daniel T., Michael J. Gill, and Timothy D. Wilson (2002), "The Future Is Now: Temporal Correction in Affective Forecasting," Organizational Behavior and Human Decision Processes, 88 (1), 430-44.

Gilbert, Daniel T., Matthew D. Lieberman, Carey K. Morewedge, and Timothy D. Wilson (2004), "The Peculiar Longevity of Things Not So Bad," Psychological Science, 15 (1), 14-19.

Gilbert, Daniel T., Elizabeth C. Pinel, Timothy D. Wilson, Stephen J. Blumberg, and Thalia P. Wheatley (1998), "Immune Neglect: A Source of Durability Bias in Affective Forecasting," Journal of Personality and Social Psychology, 75 (3), 617-38.

Gilbert, Daniel T. and Timothy D. Wilson (2007), "Prospection: Experiencing the Future," Science, 317 (5843), 1351-54.

Gould, Stephen J. (1997), "An Interpretive Study of Purposeful, Mood Self-Regulating Consumption: The Consumption and Mood Framework," Psychology and Marketing, 14 (4), $395-426$.

Gross, James J. (1998), “Antecedent- and Response-Focused Emotion Regulation: Divergent Consequences for Experience, Expression, and Physiology," Journal of Personality and Social Psychology, 74 (1), 224-37.

Gurhan-Canli, Zeynep, David Glen Mick, and Merrie L. Brucks (2003), "The Effect of Expected Variability of Product Quality and Attribute Uniqueness on Family Brand Evaluations," Journal of Consumer Research, 30 (1), 105-14.

Haugtvedt, Curtis P. and Duane T. Wegener (1994), "Message Order Effects in Persuasion: An Attitude Strength Perspective," Journal of Consumer Research, 21 (1), 205-19.

Holmberg, John and Karl-Henrik Robert (2000), "Backcasting from Non-overlapping Sustainability Principles-a Framework for Strategic Planning," International Journal of Sustainable Development and World Ecology, 7 (4), 291-308.

Hovland, Carl I. (1957), The Order of Presentation in Persuasion, Oxford: Yale University Press.

Igou, Eric R. (2004), "Lay Theories of Affective Forecasting: The Progression of Affect," Journal of Experimental Social Psychology, 40 (July), 528-34.

Jedidi, Kamel and Jacob Jacoby (1997), “A Varying-Parameter Averaging Model of On-Line Brand Evaluations," Journal of Consumer Research, 24 (2), 232-47.

Kahneman, Daniel and Jackie S. Snell (1992), "Predicting a Changing Taste: Do People Know What They Will Like?" Journal of Behavioral Decision Making, 5 (3), 187-200.

Kardes, Frank R. and Paul M. Herr (1990), "Order Effects in Consumer Judgment, Choice and Memory: The Role of Initial Processing Goals," in Advances in Consumer Research, Vol. 17, ed. Marvin E. Goldberg, Gerald Gorn, and Richard Pollay, Provo, UT: Association for Consumer Research, 541-45.

Kermer, Deborah A., Erin Driver-Linn, Timothy D. Wilson, and Daniel T. Gilbert (2006), "Loss Aversion Is an Affective Forecasting Error," Psychological Science, 17 (8), 649-53.

Lam, Kent C. H., Roger Buehler, Cathy McFarland, Michael Ross, and Irene Cheung (2005), "Cultural Differences in Affective Forecasting: The Role of Focalism," Personality and Social Psychology Bulletin, 31 (9), 1296-1309.

Linville, Patricia W. and Gregory W. Fischer (1991), "Preferences for Separating or Combining Events," Journal of Personality and Social Psychology, 60 (1), 5-23.

Loewenstein, George F. and Erik Angner (2003), "Predicting and Indulging Changing Preferences," in Time and Decision, ed.
George F. Loewenstein, Daniel Read, and Roy F. Baumeister, New York: Russell Sage Foundation, 351-91.

Loewenstein, George F. and Shane Frederick (1997), "Predicting Reactions to Environmental Change," in Environment, Ethics and Behavior, ed. Max H. Bazerman, David M. Messick, Ann E. Tenbrusel, and Kimberly A. Wade-Benzoni, San Francisco: New Lexington, 52-72.

MacInnis, Deborah J., Vanessa M. Patrick, and C. Whan Park (2006), "Looking through the Crystal Ball: Affective Forecasting and Misforecasting in Consumer Behavior," in Review of Marketing Research, Vol. 2, ed. Naresh K. Malhotra, Armonk, NY: M. E. Sharpe, 43-80.

Mellers, Barbara A. (2000), "Choice and the Relative Pleasure of Consequences," Psychological Bulletin, 126 (6), 910-24.

Mellers, Barbara A. and Peter A. McGraw (2001), "Anticipated Emotions as Guides to Choice," Current Directions in Psychological Science, 10 (6), 210-14.

Miller, Norman and Donald T. Campbell (1959), "Recency and Primacy in Persuasion as a Function of the Timing of Speeches and Measurements," Journal of Abnormal and Social Psychology, 59 (1), 1-9.

Morris, Robin and Geoff Ward, eds. (2005), The Cognitive Psychology of Planning, New York: Psychology Press.

Noori, Hamid, Hugh Munro, Gene Deszca, and Brenda McWilliams (1999), "Developing the 'Right' Breakthrough Product/Service: An Umbrella Methodology_Part A," International Journal of Technology Management, 17 (5), 544-62.

Patrick, Vanessa M., Deborah J. MacInnis, and C. Whan Park (2007), "Not as Happy as I Thought I'd Be? The Role of Affective Misforecasting in Consumer Satisfaction," Journal of Consumer Research, 33 (4), 479-90.

Pieters, Rik G. M. and Tammo H. A. Bijmolt (1997), "Consumer Memory for Television Advertising: A Field Study of Duration, Serial Position, and Competition Effects," Journal of Consumer Research, 23 (4), 362-72.

Read, Daniel and Barbara Van Leeuwen (1998), "Predicting Hunger: The Effects of Appetite and Delay on Choice," Organizational Behavior and Human Decision Processes, 76 (2), 189-205.

Richard, René J., Joop Van der Plight, and Nanne K. De Vries (1996), "Anticipated Affect and Behavioral Choice," Basic and Applied Social Psychology, 18 (2), 111-29.

Shiv, Baba and Joel Huber (2000), "The Impact of Anticipating Satisfaction on Consumer Choice," Journal of Consumer Research, 27 (September), 202-16.

Simonson, Itamar (1992), "The Influence of Anticipating Regret and Responsibility on Purchase Decisions," Journal of Consumer Research, 19 (1), 105-18.

Snell, Jackie, Brian J. Gibbs, and Carol Varey (1995), "Intuitive Hedonics: Consumer Beliefs about the Dynamics of Liking," Journal of Consumer Psychology, 4 (1), 33-60.

Stone, Arthur A., Susan M. Hedges, John M. Neale, and Maurice S. Satin (1985), "Prospective and Cross-Sectional Mood Reports Offer No Evidence of a 'Blue Monday' Phenomenon," Journal of Personality and Social Psychology, 49 (July), 129-34.

Tabachnick, Barbara G. and Linda S. Fidell (1996), Using Multivariate Statistics, New York: HarperCollins.

Tversky, Amos (1977), "Features of Similarity," Psychological Review, 84 (4), 327-52.

Tversky, Amos and Itamar Gati (1978), "Studies of Similarity," in Cognition and Categorization, ed. Eleanor Rosch and Barbara B. Lloyd, Hillsdale, NJ: Erlbaum, 42-62. 
Tversky, Amos and Daniel Kahneman (1974), "Judgment under Uncertainty: Heuristics and Biases,” Science, 185 (4157), 1124-31.

Varey, Carol A. and Daniel Kahneman (1992), "Experiences Extended across Time: Evaluation of Moments and Episodes," Journal of Behavioral Decision Making, 5 (3), 169-85.

Wilson, Timothy D., David B. Centerbar, Deborah A. Kermer, and Daniel T. Gilbert (2005), "The Pleasures of Uncertainty: Prolonging Positive Moods in Ways People Do Not Anticipate," Journal of Personality and Social Psychology, 88 (1), $5-21$.

Wilson, Timothy D. and Daniel T. Gilbert (2003), “Affective Fore- casting," in Advances in Experimental Social Psychology, Vol. 35, ed. Mark Zanna, San Diego, CA: Academic Press, 345-411.

Wilson, Timothy D., Thalia P. Wheatley, Jonathan M. Meyers, Daniel T. Gilbert, and Danny Axsom (2000), "Focalism: A Source of Durability Bias in Affective Forecasting," Journal of Personality and Social Psychology, 78 (5), 821-36.

Zeelenberg, Marcel J., Jane Beattie, Joop Van der Plight, and Nanne K. De Vries (1997), "Consequences of Regret Aversion: Effects of Expected Feedback on Risky Decision Making," Organizational Behavior and Human Decision Processes, 65 (2), 148-58. 